San Jose State University

SJSU ScholarWorks

Faculty Publications

Valley Foundation School of Nursing

$1-1-2011$

\title{
The lived experience of students in an accelerated nursing program: Intersecting factors that influence experiential learning
}

\section{Susan McNiesh}

San Jose State University, susan.mcniesh@sjsu.edu

Follow this and additional works at: https://scholarworks.sjsu.edu/nursing_pub

Part of the Nursing Commons

\section{Recommended Citation}

Susan McNiesh. "The lived experience of students in an accelerated nursing program: Intersecting factors that influence experiential learning" Journal of Nursing Education (2011): 197-203. https://doi.org/ 10.3928/01484384-20101029-03

This Article is brought to you for free and open access by the Valley Foundation School of Nursing at SJSU ScholarWorks. It has been accepted for inclusion in Faculty Publications by an authorized administrator of SJSU ScholarWorks. For more information, please contact scholarworks@sjsu.edu. 
Lived experience of students- 1

Running head: THE LIVED EXPERIENCE OF STUDENTS

The Lived Experience of Students in an Accelerated Nursing Program: Intersecting

Factors that Influence Experiential Learning

Susan McNiesh, PhD, RNC

San Jose State University 
Accelerated nursing programs are becoming commonplace in response to the interest of second baccalaureate degree students in nursing, as well as in response to the nursing shortage. According to the American Association of Colleges of Nursing (2005), accelerated baccalaureate degrees in nursing (BSN) programs are the fastest growing type of entry level nursing programs in the United States. Though not as prolific, as of a 2007 survey by AACN (American Association of Colleges of Nursing, 2007) there were 56 master’s entry nursing programs nationwide and 13 more were in the planning stages. Masters entry programs are appealing to those with non-nursing baccalaureate degrees and prior career trajectories since these programs build on these former skill sets and allow students to jumpstart and enter the field as advanced practice nurses. These programs tap into a new and highly talented student population, yet many schools have not tailored their curricula to meet the needs of this richly experienced group.

Literature review

Accelerated students fit the profile of adult learners (Cangelosi, 2007; Miklancie \& Davis, 2005; Seldomridge \& DiBartolo, 2005), with a variety of life experiences (American Association of Colleges of Nursing, 2005; Shiber, 2003) and self-motivation (Meyer, Hoover, \& Maposa, 2005; Miklancie \& Davis, 2005). These students hold higher expectations of the academic experience; therefore, they are intolerant of busy work, challenge faculty, and expect current teaching practices (American Association of Colleges of Nursing, 2005; Cangelosi, 2007; Miklancie \& Davis, 2005). Yet they acknowledge the limits of their experience, and feel a strong need for more clinical hours and more meaningful clinical experiences during their education (American Association of Colleges of Nursing, 2005; Cangelosi, 2007; Shiber, 2003; Weitzel \& McCahon, 2008). Student responses suggest that program pedagogies should acknowledge and incorporate their prior life and educational experiences (Cangelosi, 2007; Shiber, 2003). The 
personal financial difficulties of full time study (American Association of Colleges of Nursing, 2005; Siler, DeBasio, \& Roberts, 2008) and the stress due to the time limitations and workload of an accelerated curriculum (Meyer, Hoover, \& Maposa) are the main hardships reported. While these studies give a demographic profile of students in accelerated programs and a snapshot of students' expectations and stressors during their course of study, there is scant current literature on the day to day experience of nursing students in accelerated programs as they take up the practice of nursing, and there is no current literature on the experience of master's entry nursing students taking up the practice during their course of study.

\section{Study Design}

The goal of an interpretive account is to develop a thick description (Geertz, 1973/2000) that reveals a salient articulation of the lived experience of the study phenomenon. The researcher provides a holistic account of the person in the situation and strives to describe and interpret what was disclosed and what might have gotten 'covered over' (Heidegger, 1927/1962), another way of describing tacit understanding. In addition, the lived experience of individuals in situations gives the readers access to the culture because "the participant's voice is not a privatized, purely subjective voice but rather an embodiment and lived understanding of a world and set of local clearings created by social groups, practices, skills, history, and situated events" (Benner, 1994, pp. 100- 101).

Hubert Dreyfus (1999) describes three interrelated and foundational aspects of human intelligent behavior within situations as: "the role of the body in organizing and unifying our experience of objects, the role of the situation in providing a background against which human behavior can be orderly without being rule-like, and finally the role of human purposes and needs in organizing the situation so that objects are recognized as relevant and accessible” 
(p.234). In a comparable way there exist shared background understandings and newly formed meanings for nursing students that include skills and practices, how students encounter and use objects as equipment, and how students relate to others.

The overall goal of this interpretive phenomenological study was to articulate the lived experience of students in an accelerated master's entry program learning the practice of nursing within a clinical setting. Specific research questions included: How did previous life experiences, education, and career choices influence the experience of second degree students? What were the potential effects on learning of condensing and accelerating the curriculum as is requisite in second degree programs?

Sample

Following institutional approval, students from an accelerated master's entry program in nursing (MEPN) located within the western United States were purposively recruited for this study. Eligibility was limited to students who were in the first year of the program at the specified research site, were currently enrolled in a clinical practicum, and agreed to participate in the study. Since more applicants were available than the target number desired, the investigator chose subjects based on achieving a maximum representation along gender, racial, and ethnic categories as well as background experiences of educational, employment, and other personal factors $(\mathrm{n}=19)$. Achieving diversity in the sample is not essential for an interpretive study, however it can provide a broader range of standpoints from which a particular experience can be told (van Manen, 1990).

\section{Data collection}

Audiotaped interviews with the nursing students as well as observations of students in their clinical roles were the major data collection strategies. Field observations of students 
engaged in the care of patients revealed background details that remained hidden to students within their tacit understanding of care (Benner, Tanner, \& Chesla, 1996). These observations provided an additional source of data as students' narrative accounts could preclude these details.

During the first year of this study four students participated in individual interviews throughout the school year. Three of these students were interviewed on four occasions; the fourth person was interviewed only three times due to a difficult family circumstance. The following year 15 first year students were interviewed throughout the school year, initially in small group format, followed by two one-to-one interviews, and ending with another small group interview. Interspersing two types of interview formats gave access to different types of data, as the group interviews tended to take on conversational overtones among the participants, as one student's narrative precipitated recall of another student's account.

Interviews lasted 60- 90 minutes and were conducted in a confidential setting. As much as possible students were asked to tell a story about their involvement in actual situations of care, beginning with their first encounters in the clinical setting. Benner, Hooper-Kyriakidis, and Stannard (1999) considered narratives as a particularly effective strategy to access the experiential learning of individuals in clinical settings since they give a sense of time, place, and characters within the story and capture what is important to the teller. Narratives are told in everyday language replete with multiple meanings, nuances, and ambiguity (Chesla, 1995).

\section{Data analysis}

While descriptive phenomenology calls for the researcher to use a bracketing technique to set aside the researcher's preunderstandings, interpretive phenomenology considers this forestructure as essential as the place from which one has a point of view and from which the researcher can make meaningful distinctions in interpretation (Heidegger, 1927/1962; Leonard, 
1994; Packer \& Addison, 1989b). In hermeneutic inquiry, meaning is not derived from outside but rather from within a circle or clearing (Allen, 1995), referred to as the hermeneutic circle. The concept of the hermeneutic circle influenced this methodological inquiry in every way. It formed the background understandings that grounded the problematizing of the study, the research design, and the interpretation (Packer \& Addison, 1989a).

The interviews were transcribed verbatim, and listened to not only to verify the accuracy of the text but also to note pauses, inflections, or silences as these might signal areas of meaning that had been covered over. Analysis began by reading through the entire interview, observation notes, and other background information to get a sense of the whole. Interpretation proceeded by moving back and forth between parts and whole, between my initial forestructure and what was being revealed (Geertz, 1973/2000), creating iterative cycles of understanding (Benner, 1994) As initial interviews were interpreted, lines of inquiry were delineated and these were integrated into subsequent interviews. Evaluation of interpretation occurred during interviews as I verified my understanding of participants’ statements by asking clarifying questions or paraphrasing my understanding of the participant's account.

Interpretive notes were written during and after each reading of the narrative text. After reading all texts, I became immersed in the data for overall feel, “questioning, comparing, and imaginatively dwelling in their situations” (Benner, 1994, p. 99). Next, I aimed to articulate paradigm cases and exemplars from interpretation of the narratives. A paradigm case is "a strong instance of particular pattern of concerns, ways of being in the world, or ways of working out a practice” (Benner, Tanner, \& Chesla, 1996, p. 361) that allows other less obvious instances with similar characteristics to be recognized in relation to it. An exemplar, though smaller than a paradigm case, is a vignette that captures the meaning of a situation to the individual as 
experienced (Benner, 1994). Thus, paradigm cases and exemplars were used as strategies for explicating shared meanings within the culture.

\section{Findings and Discussion}

The findings begin with a paradigm case that illustrates the interactive and co-constitutive effects of a condensed and accelerated curriculum, the high stakes learning situations experienced by a group of bright, idealistic, and driven students, and the intrusive quality of everyday life concerns. In the student's own words, this narrative was about "the layering of everything else that's going on in your life” along with participation in an accelerated curriculum. The term co-constitutive is used to emphasize how each aspect is fundamentally changed through the interaction with other aspects.

Betty's (a pseudonym) narrative of breakdown occurred during the medical/surgical quarter that builds on skills learned in the first quarter of their nursing program. The students considered this the most intense and physically demanding quarter since each week included two full eight hour days of lecture, then two consecutive 12-hour clinical days as well as weekly prelab, intensive clinical preparation for the care of a specific patient, and periodic day long observations in selected clinical settings. It was also the setting with the most acutely ill patients and during this time students were expected to learn to manage care on their own, as Betty related:

I think yeah, the med-surg was the most demanding. Forget the physical part of it, because that doesn’t bother me ever, but to integrate all the learning so quickly ... And then I have this totally distracting personal layer on top of it all, leading me close to a nervous breakdown. 
The narrative continued with Betty recalling a phone call from the social worker at the skilled nursing facility where she had recently placed her mother:

We need to talk about moving her to the Alzheimer's unit ... except she'd be in a bed, one of three in the room in the middle. And all I can envision is her crawling into bed with someone routinely at night ... And then I get distracted from the care, which already is really fast paced ...I'm a very intense person ... I just vibrate like this from in there (she places her clenched fist to her chest and pounds it softly) .... And dealing with people’s lives ... there’s very little room for making mistakes...the level of acuity is definitely increasing, and the demands on us are increasing. And we're supposed to be handling two patients pretty autonomously at this point ... I could spend four hours pre-labbing on each patient ... I really want to be solid with what I'm doing ... I go in fairly unsure because of the lack of experience. .. I took care of a guy who had a bucal cell carcinoma who had had a flap from his forearm basically sewn, a free flap sewn into his cheek. Because they had to remove his cheek and then use other tissue. And he was trached ... And there's only so much I can pre-lab. And then the experience of doing a deep suction on a trach patient was totally intimidating. Well thankfully the nurse that I was working with stepped in and showed me how to do it ... I did not feel comfortable at all. I'm practicing on this person who had half of his cheek cut out and just looking at this person is totally intimidating.

Betty’s family was a significant factor in the narrative. Her mother had recently been admitted to a skilled nursing facility, and Betty was the primary decision maker concerning her mother’s care. In addition, Betty’s daughter was ill and her husband needed to travel out of town. In a last 
minute arrangement, Betty enlisted her father to care for her ill daughter. It was clear that Betty was a driven, dedicated student who wanted to enter the clinical day with maximum preparation, before giving care to her patients as a novice. Within the pace of the accelerated program she understood the expectation to handle the care of two patients at this juncture. As it happened one of her patients was a very visibly debilitated patient who required a high stakes procedure (maintaining a clear airway on a tracheostomy) that Betty had never performed. Continuing her account, Betty described a brief encounter with a nurse:

And then I walked into the day, and the nurse I had been working with for two days prior, who’s a fabulous nurse-great teacher ... Perfect nurse ... I came in and one of the first things that she said to me was, "Betty, we have to look at your charting." And it was a totally benign comment on any other day, but the tone that I heard was, “you’ve been bad” ... And unfortunately we didn’t have the opportunity at that moment to talk, to review the charting, to get specific about what was going on. I mean it was like someone saying ... I don’t like you. And then walking away... it just pushed me over the top ... It just knocked my confidence to my knees ... So I started to get flustered and started to cry, and I couldn't keep it down. I tried ... and any other day it would have just been: okay, can we talk about this at noon ... But this layer upon layer upon layer and then I had to take care of patients competently, and I just couldn't do it. ..So ultimately I left ... I was so at the risk of making mistakes ... It's too big of a job to be distracted like that ... But any other day it probably wouldn't have affected me like it did. It was just that day in that moment. In the end, Betty's breakdown was precipitated by her perception of an ill-timed but corrective remark by a nurse whom Betty respected as a role model and teacher. Perhaps the 
nurse did not foresee the effect this would have on Betty. Stopped in her tracks Betty interpreted the remarks as a criticism of her whole person. Yet ultimately this emotional response led Betty to realize that she was unable to provide safe patient care on that day, thus demonstrating her taking up of an ultimate good of nursing practice, safe patient care over her own learning and performance agenda.

Exemplars of student and world

Betty’s story is presented as a paradigm case because of its power to illustrate the synergistic impact of the demands and stress of her family dynamics alongside the fast-paced, physical, high risk learning of nursing practice. As noted in the literature review and illuminated in the paradigm case, students attracted to accelerated programs are highly motivated and confident of their academic abilities yet feel less effective and assured in their abilities to perform clinically. The following exemplars further illuminate who these students are, as well as the context of care they experience as they take up the practice of nursing over time.

Entering a foreign world. Upon entering the clinical world students were overwhelmed by the unfamiliarity of the environment. Students in accelerated programs often enter the clinical floor during the first or second week of their schooling. Students described this as being “plunged right in” or "hitting the ground running”, or "being put out on our own”. There were no maps or operating instructions to help the students find their way and create order from chaos in order to function ("I'm one of those people that likes to read all the instructions on the back of something before I use it”). There was no sense of context or grounding, no prior experience with which to confront and cope with acutely ill people and medical personnel using oddly foreign social conventions as noted in this student narrative: 
The hospital is like a totally foreign country ... Time is totally different, it's constantly this weird light; there's no natural light going on, and it's all these weird noises and beeps that you don't understand. And then there's the language. I didn't understand probably three -quarters of the conversations going on in the halls, between doctors, between doctors and nurses, and the pharmacists. .. It's a totally foreign language and it reminded me of the times that I've traveled to foreign countries and just ultimate culture shock of what's going on, where am I, how do I even, what are the right behaviors in this environment? ...the very first time you meet somebody you ask them how their bowel movements were. And, I'm sorry; I have never just met somebody for the very first time and asked them the last time they had a bowel movement.

Everything was unfamiliar: smells, sights, sounds, and even time. Light was unnatural and constant, and there were unknown beeps. The language was only vaguely familiar, with the use of acronyms peppered into most conversations. It was akin to being in a foreign land where the customs were remarkable, as for example, meeting someone for the first time and asking about typically private bodily functions.

Novice again in a new world. These novice students' response to the newness of the clinical world was heightened by their prior sense of being at home in a familiar work environment. In their first clinical experience they encountered just how novice they were, how foreign this new terrain was, and how much they needed to learn.

A student compared the clinical learning to "almost having a job" that included a practical side of learning important but mundane knowledge, such as the operation and significance of the call light: "knowing where the call light button was- I didn't know that for a 
few weeks. It was like no one had pointed that out to me... it just magically appeared and would blink and I didn’t know where it came from — And how you turn it off.” Students felt clumsy, slow, and inefficient ("bogged down in those little nuances”) in comparison to the observed actions of the nurses on the floor who "do everything so seemingly flawlessly, efficiently, with grace.” Not knowing the very basic skills made students “stick out like a sore thumb”. More significantly, all of these background details confused and obfuscated the student's attempts to gain a sense of salience: “obviously you can learn how to work the phone and silly things like that... and that shouldn't be given the same priority as doing an accurate manual blood pressure or something like that. But this just adds to the not knowing.”

Not knowing the mundane made navigation in the new environment difficult and created social embarrassment for the students. This seems like an easy problem to fix with skills labs focused on the everyday and mundane, billed in just such a manner, so that the students are clear that these aspects of clinical are not difficult, nor even the focus of their clinical learning, but are provided primarily to smooth the student's practical and social transition to the clinical environment. These skills are orienting aspects that need to be put in the background for more significant clinical learning to occur as soon as possible.

Students in accelerated programs came with prior experience of mastery in an academic setting and often had successful, varied and challenging career trajectories. After being out in the world as successful individuals they were once again thrown into a world with little background understanding to ground them, and experienced feeling novice again. Being a novice was similar to being a tourist or new immigrant who does not yet know the common language, habits and practices, or how to get around in a new environment. Now they were aware of no longer being competent, of feeling a loss in confidence and ability. They came with both explicit and tacit 
expectations about their job performance capabilities and these expectations were quickly challenged and unraveled.

Perhaps more significantly, their former academic and career pursuits appeared structured, ordered, and predictable compared to the seemingly chaotic, high knowledge-skill, yet underdetermined relational world of nursing. These students entered the accelerated nursing program with a drive towards perfection, and with some expectation that this accelerated program would mirror their former academic experiences (Lockwood, Walker, \& Tilley, 2009). Students with prior experience of successful career trajectories and academic success may be more optimally positioned for certain aspects of an accelerated program (academic learning, critical thinking and the ability to synthesize knowledge, and perhaps aspects of the ability to be with people). Yet coming from a more circumscribed world there are aspects of their prior beingin-the-world that might hamper them in embracing an underdetermined practice such as nursing.

The physical demands of nursing work. A rarely articulated part of taking up the practice of nursing is the demanding schedule of hospital shift work, and the physical demands of working with patients. Not only did students complain about the hardship of 12 hours on their feet but also the need to wake up before dawn to commute for an hour and arrive on time for a shift report. The students were challenged to develop a rhythm of waking and sleeping to accommodate the early start time of hospital shifts. This altered schedule was more difficult to accommodate when students were anxious about confronting the new clinical world. In addition to learning a new work world, the students had to learn new time patterns, and new physical demands.

The pace of learning for clinical assignments The condensed timeframe for clinical education was physically and emotionally tiring so that students had less stamina to confront the 
intensive reading and other aspects of their coursework. Every day was at an accelerated pace heightened by “doing things I’ve never done before.” One student suggested being in an accelerated program was "the microwave version" of learning nursing as compared to the "slowbaked kind" in a four year traditional baccalaureate curriculum. As one student remarked about the fast-paced momentum, “Your program is so accelerated that it's like you don't have time for missteps.” Students acknowledged they entered the program fully aware of the potential for intense stress. "I signed up for intensity, and powering through a lot of material and a lot of learning in a small amount of time...but it’s still stressful.”

Sleep, exercise, eating well, and "balancing” the rest of their lives with the demands of the program often emerged as key to tolerating the rigors and stress of an accelerated program. One student felt the program administrators relayed a message "that our personal lives and some sort of balance isn't important...figure out how much your family needs and how much time you're going to have with them and then expect to spend less than half of that.” Unfortunately, part of the hidden curriculum was that family care, personal health, exercise, sleep and rest were not endorsed by some faculty since this hidden curriculum message conflicts with their overt teaching about the importance of a balanced life for health promotion and illness prevention.

What is at stake. Students were well aware of the implications of their actions as nursing students. People’s lives were in their hands: “I knew that you're responsible for possibly somebody's life... it's not like you forget to mail something and sure that could be terrible and maybe you'll lose your job, but you could overdose and you could kill somebody!”

Nursing includes attention to details that matter to someone's well-being compared to past errors of forgetting to mail an important letter. One student noted that this attention to detail needs to be sustained throughout the work day; that creates in some students a sense of continual 
hyper-vigilance so that nothing is missed ("nursing is incredibly detail-oriented, and it seems like you have to maintain a high level of being detail-oriented all day long consistently. And I think it's really draining”). Even as early as the first day of clinical, students were confronted with the possibilities and what is at stake:

It was terrifying. I remember being absolutely scared and uncomfortable. I’d never been around acutely ill people ever. I had no context to begin to understand... At the first orientation they show you where the crash cart is ... The hospital gives you the policies and the procedures and if anyone did code, you would be expected to start CPR—And I remember the first couple weeks being asked to feed patients, and what a scary, terrifying thing it was to be asked to feed a patient who has a risk for aspiration and you have to make sure they're sitting up totally upright and they're chewing all their food and they're swallowing. Something that you would think would not be scary.

Initially swept up in strangeness, the student felt terrified because the possible dangers for her patients felt real but ill-defined. There seemed to be few touchstones on which to build understanding. Almost immediately the student was confronted with the hospital reminder of the reality of death: the code blue cart. The once benign act of helping to feed a patient became “terrifying” when the student was made aware of the dangers of aspiration for certain patients. There was an overwhelming sensitivity to the notion that rather than helping a patient the student could unwittingly harm someone. Yet students felt that this sense of responsibility was actually a necessary context in a high stakes learning environment: the risks were real, and it was better to know them than ignore them. 
Students sensed the vulnerability of patients, patients who were sometimes at the very beginning or near the end of their lives, or in debilitated and suffering states. And while patients were in these vulnerable states, fledgling medical personnel practiced on them, as in this student's observation of a respiratory therapist in training:

There is a level of danger of just nursing school, or training people in medical school... Are you kidding me? This person is going to do this procedure and they never have before? Who wants to be the one who gets that procedure the first time? Not me, thank you ... I was with this guy yesterday who was just doing arterial blood gases and he’s like "If I get one out of four that's not bad.” It wasn't only nursing students that were involved in high stakes situations. In this situation the student was talking about a novice respiratory therapist drawing blood gases in an intensive care unit. This student as a lay person appropriately identified more with the patient than with the learner. The challenge in professional education is to maintain this patient-centered focus throughout the educational program. Students, even respiratory students, need to have an ethical escape clause for their learning. Sometimes the timing is too crucial and learning needs to be deferred for the sake of the patient. Moreover, student participants seldom spoke of using their clinical instructor as a safety net even though they were often caring for acutely ill patients. Instead, students took up a posture of hyper-responsibility.

\section{Experiential learning}

A practice, such as nursing is a cluster of patterned and interrelated ways of being that relies on socially embedded practical knowledge (Dunne, 1997). In other words, there is no discrete set of content that stands alone and apart from the practice setting. Rather, practical knowledge is learned through concrete clinical encounters alongside practitioners with more 
experience (Benner, Tanner, \& Chesla, 1996). Nursing practice demands this situated cognition, learning while doing within a concrete clinical situation (Lave \& Wenger, 2006). Students were struck by how much they didn’t understand, yet what stands out in these students' accounts of “doing things I’ve never done before” is a context where people’s lives are at stake within the learning environment.

Being part of an intense learning community. Most of the students used the term Type A to describe themselves as well as their fellow students. Their descriptions included: "very motivated and driven”; “bit of an all stars group”; “intense, take themselves seriously”; “well cast, smart, and proactive”; “extremely academically demanding”; “a very driven, hard working group"; "very sure of themselves and outspoken”. One student described the difficulty of being a highly motivated personality in an accelerated program: “The personality wants to do it all, to read everything and live at the library.” Another student commented favorably on the intelligence and shared goals and beliefs of her classmates and acknowledged that this added to the academic experience.

However, the fact that students "take themselves too seriously" made it hard to be around them all the time. As another student described the group, "I think all the MEPNs in the program are overachievers, and...I think it's a blessing and it's a curse.” Study participants described how students' anticipation and excitement heightened the atmosphere of expectation and stress while at the same time acknowledging their classmates’ sense of transitions in their identity and accomplishments:

And the second thing is the sheer enthusiasm of all our classmates, kind of just multiplied... I mean everyone is feeling pressure. Everyone is trying to prove to themselves that they can do this. Everyone's making identity shifts. I mean most 
people are coming from a different identity. And so we're all in this. And then when it all comes together, it's just like a storm of emotion and expectations. So the energy kind of feeds off each other.

Students formed an intense but extremely useful learning community. The "blessing” of being within this learning community quickly became evident during the group interviews. After the initial interview question was framed, students typically would articulate answers in a dialogical format, frequently adding to the comments of the other student with little need for the interviewer to intercede. Within this community of learners, students sensed the ways in which the transformations in themselves and their classmates were both personal and social as they shared and negotiated meanings of their practical experience in the clinical setting (Lave \& Wenger, 2006).

Within this research study group, practical knowledge was also shared among the intense but extremely useful peer members in the learning community. The students' rich and varied backgrounds, intelligence, shared goals and beliefs, and their intensity all contributed to enriching their shared experience of taking up the practice of nursing in an accelerated learning community (Lave \& Wenger, 2006). Student accounts richly described the social embeddedness of knowledge within their learning community as the group engaged in dialog and shared the changes in their understandings of clinical situations over (Benner, Tanner, \& Chesla, 1996). As described by this study's participants, "the students are the best part of this program."

\section{Implications}

This interpretation of students' lived experiential accounts reflects the contradiction and ambivalence of their experience within an accelerated learning environment and community. Comparable programs should enlist faculty for such programs that are willing to embrace the 
complexity and particular challenges of this learning community. In addition, this research underscores the important and pivotal role of clinical faculty, guiding the student towards more independent practice but never at the expense of patient safety or a student's mistaken perceptual grasp of what is significant in a particular patient encounter.

Nursing faculty can guide students to develop an anticipatory set to deal with uncertainty, especially useful for people coming from success and competence in a more circumscribed world. Clinical faculty can encourage the students' understanding of the practice by frequent questioning of students about their patients in such a way that meanings are brought up from the background. One of the problems of practical reasoning is that it depends on recognizing the nature of the situation, i.e. what stands out as more or less important (Bourdieu, 1977), but this grasp of the nature of a complex and under-determined clinical situation eludes the novice who has little experience with different clinical situations. Benner et al describe the role of experience in the development of clinical reasoning in a particular situation. For the novice, and even the advanced beginner, aspects of the clinical situation can appear of equal weight and it is up to clinical faculty to coach students and help them notice and interpret the details that are of most significance (Benner, 1984; Benner, Tanner, \& Chesla, 1996).

The range and sheer number of “small” things to learn can be disorienting and increase students’ vigilance about everything; even though they readily recognize that some things are more important than others. The lack of orientation to these small things underscores their takenfor-grantedness. Time in the skills lab orienting to hospital beds, call lights and even phone systems can take some of this pressure off for the students. The learning goal is to avoid having the student feel insulted or their intelligence demeaned by these simple, yet major entrée skills required to navigate the clinical environment smoothly. 
Clinical faculty can also act as cultural brokers. When students enter the clinical world, they are required to change the boundaries of their social access (Benner, Sutphen, Leonard, \& Day, 2009) as the skills of involvement with patients are concerned with completely new social and emotional boundaries and concerns. Early in their clinical practice students may not yet understand the implications and significance of personal questions about bodily functions. In addition, students may not yet feel the sanction of the role sufficiently to feel comfortable in asking questions about what would have always been experienced as private bodily functions and personal space, and thus off limits to a stranger, in all their former life experiences. Having students rehearse with each other, with coaching from the instructor, could help diminish some of the strangeness and clarify the relevance of the questions. In addition, if students are taught patient care skills effectively as more than de-situated psychomotor skills, intimate moments with patients can open up the student's understanding of the patient's particular concerns, and also provide insights into the cultural expectations for the relational aspects of being a nurse.

\section{Conclusion}

Clinical learning situations often involve “a level of danger” in “dealing with people’s lives” where "there’s very little room for mistakes.” While the concentrated, fast-paced nature of accelerated programs and the potential intrusion of everyday life concerns are unavoidable, there are guides and framings that faculty can provide to enable the initial passage of students into the clinical world as well as to help the student navigate the continually uncertain terrain of experiential learning in a climate of patient safety.

From this study, it appears that these second degree students felt more urgency sooner than the generic baccalaureate student to take up primary care of patients, while also displaying an acute understanding that "lives are at stake”. Students entered the program intensely 
motivated with a background of high accomplishment and hard work. The expectation of both faculty and students was that these students are primed for success in an accelerated program. Also in the background was time pressure; an expectation that the students would be 'ready' to enact the staff nurse role by the end of the first year. Likely the confluence of these aspects were at play in the students' early and earnest sense of responsibility. Their background of assuming responsible work roles may have added to their readiness to take on responsibility. What is significant, yet taken for granted, is for clinical faculty to encourage the students' developing sense of agency and identity while guiding the student to develop a practice that accepts the safety nets necessary in 'high stakes' experiential learning. 


\section{References}

Allen, D. (1995). Hermeneutics: Philosophical traditions and nursing practice research. Nursing Science Quarterly, 8(4), 174-182.

American Association of Colleges of Nursing. (2005). Accelerated programs: The fast track to careers in nursing. AACN Issues Bulletin Retrieved August 30, 2009, from http://www.aacn.nche.edu/Publications/issues/Aug02.htm

American Association of Colleges of Nursing. (2007). Fact Sheet: Accelerated baccalaureate and master's degrees in nursing. Retrieved April 21, 2008, from http://www.aacn.edu/Media/FactSheets/AcceleratedProg.htm

Benner, P. (1984). From novice to expert: Excellence and power in clinical nursing practice. Menlo Park, CA: Addison-Wesley.

Benner, P. (1994). The tradition and skill of interpretive phenomenology in studying health, illness, and caring practices. In P. Benner (Ed.), Interpretive phenomenology: Embodiment, caring, and ethics in health and illness (pp. 99-128). Thousand Oaks, CA: Sage.

Benner, P., Hooper-Kyriakidis, P., \& Stannard, D. (1999). Clinical wisdom and interventions in critical care: A thinking in action approach. Philadelphia: Saunders.

Benner, P., Sutphen, M., Leonard, V., \& Day, L. (2009). Educating nurses: A call for radical transformation. San Francisco: Jossey-Bass.

Benner, P., Tanner, C., \& Chesla, C. (1996). Expertise in nursing practice: Caring, clinical judgment, and ethics. New York: Springer.

Bourdieu, P. (1977). Outline of a theory of practice (R. Nice, Trans.). Cambridge, UK: Cambridge University Press. 
Cangelosi, P. R. (2007). Voices of graduates from second-degree baccalaureate nursing programs. Journal of Professional Nursing, 23(2), 91-97.

Chesla, C. A. (1995). Hermeneutic phenomenology: An approach to understanding families. Journal of Family Nursing, 1(1), 68-78.

Dreyfus, H. L. (1999). What computers still can't do: A critique of artificial reason. Cambridge, MA: MIT Press.

Dunne, J. (1997). Back to the rough ground. Notre Dame, Indiana: University of Notre Dame Press.

Geertz, C. (1973/2000). The interpretation of cultures. New York: Basic Books.

Heidegger, M. (1927/1962). Being and time (J. Macquarrie \& E. Robinson, Trans.). New York: Harper \& Row.

Lave, J., \& Wenger, E. (2006). Situated learning: Legitimate peripheral participation. New York: Cambridge University Press.

Leonard, V. W. (1994). A Heideggerian phenomenological perspective on the concept of person. In P. Benner (Ed.), Interpretive phenomenology (pp. 43-64). Thousand Oaks, CA: Sage.

Lockwood, S., Walker, C. A., \& Tilley, D. S. (2009). Faculty perceptions of an accelerated baccalaureate nursing program. Journal of Nursing Education, 48(7), 406-410.

Meyer, G. A., Hoover, K. G., \& Maposa, S. (2005). A profile of accelerated BSN graduates, 2004. Journal of Nursing Education, 45(8), 324-327.

Miklancie, M., \& Davis, T. (2005). The second-degree accelerated program as an innovative educational strategy: New century, new chapter, new challenge. Nursing Education Perspectives, 26, 291-293. 
Packer, M. J., \& Addison, R. B. (1989a). Evaluating an interpretive account. In M. J. Packer \& R. B. Addison (Eds.), Entering the circle: Hermeneutic investigation in psychology (pp. 275-292). Albany: State University of New York Press.

Packer, M. J., \& Addison, R. B. (1989b). Introduction. In M. J. Packer \& R. B. Addison (Eds.), Entering the circle: Hermeneutic investigation in psychology

(pp. 13-36). Albany, NY: State University of New York Press.

Seldomridge, L. A., \& DiBartolo, M. C. (2005). A profile of accelerated second bachelor's degree nursing students. Nurse Educator, 30(2), 65-68.

Shiber, S. M. (2003). A nursing education model for second-degree students. Nursing Education Perspectives, 24(3), 135-138.

Siler, B., DeBasio, N., \& Roberts, K. (2008). Profile of non-nurse college graduates enrolled in accelerated baccalaureate curricula: Results of a national survey. Nursing Education Perspectives, 29(6), 336- 341.

van Manen, M. (1990). Researching lived experience: Human science for an action sensitive pedagogy. New York: State University of New York

Weitzel, M. L., \& McCahon, C. P. (2008). Stressors and supports for baccalaureate nursing students completing an accelerated program. Journal of Professional Nursing, 24(2), 8589. 